\title{
Multi-criteria approach for strategic planning of reverse supply chain
}

\author{
Abdelkader Benzohra ${ }^{a^{*}}$ and Myriam Noureddine ${ }^{b}$ \\ ${ }^{a, b}$ Department of Computer Science, Faculty of Mathematics and Computer Science, University of Science and Technology of Oran (USTO-MB) B.P. \\ 1505 El-M'Naouer, 31000 Oran, Algeria \\ C H R O N I C L E \\ Article history: \\ Received October 3, 2016 \\ Received in revised format: \\ October 22, 2016 \\ Accepted November 10, 2016 \\ Available online \\ November 112016 \\ Keywords: \\ Reverse supply chain \\ Domestic waste \\ Plans \\ Criteria \\ Outranking relations

\begin{abstract}
A B S T R A C T
A reverse supply chain is viewed as a process from consumption point to recovery point and the management of domestic waste is considered as a specific and complex reverse supply chain. This important sector represents a high challenging problem for our cities, constrained by financial, social, health and environmental considerations. This paper proposes multicriteria decision aid to help choose an efficient domestic waste management strategy. In fact, Multicriteria decision making techniques are considered as a key option to solve this type of problems, giving a solution that represents a good compromise between different preferences. The adopted approach consists in outranking a set of candidate management plans using a method based on partial aggregation criteria. This model is applied on a real case study of an Algerian city and to validate the obtained results, a deep sensitivity analysis is carried out,
\end{abstract} \\ giving the most appropriate plans.
}

(C) 2017 Growing Science Ltd. All rights reserved.

\section{Introduction}

In high concurrency and productivity era, a large amount of end of life products and waste are generated. This flow represents a real challenge that should be overtaken. This cannot be attained without a good logistics strategy. The management of this flow is called Reverse Logistics (RL). RL is an emergent extension of the conventional logistics or Forward Logistics (FL). RL is the management of the Reverse Supply Chain (RSC) resulting from the product flow from consumption point to disposition point. Domestic Waste (DW) Management (DWM) is an important application of the RL. The complexity in this area is due to the numerous constraints to take into account in the planning process like costs, environment and health effects, but also the maximisation of revenues from product recovery. In addition, the planning process must take all these parameters into account at the same time.

* Corresponding author.

E-mail address: aek.benzohra@gmail.com (A. Benzohra)

(c) 2017 Growing Science Ltd. All rights reserved. doi: $10.5267 /$ j.ds1.2016.11.003 
DWM as a RSC differs from Forward Supply Chain (FSC) in many aspects, so Decision Makers (DM) must take into consideration this specificity in planning process.

The quantity of generated DW by Algerian households was estimated to be 700 thousand tones/year which represent a value of 3.5 billion DZD. And this fortune terminates usually in landfills due to the inefficient DWM plans (Guide , 2009). If we consider that the collection and disposition of one Tone cost 4500 DZD (Guide , 2009), the global value can be estimated to 3 billion of DZD/year. In addition to economic inefficiency the actual management strategy implies also environmental and social problems. Many researchers consider that the motivations of RSC are the same as the sustainable development (economic, environmental and social) (Millet, 2010). Brito et al. (2002) classify the RL driving forces into three categories i.e. economic, legislative and aspects relative to the extended responsibility of enterprises.

These complications justify our choice to use Multicriteria Decision Making (MCDM) approach to deal with all those dimentions. MCDM is considered as an important technique to solve multi-objective problems. Especially, outranking based methods are very interesting to overcome the problem of transitivity and complete comparability between alternatives. And the method we adopted permits to deny compensation of critical criteria like those relative to health and environment. Moreover, this method takes in consideration data uncertainties which are always present in such context. Our model is applied on data gathered from an Algerian seaside municipality. We issue endogenous criteria that reflect the DM preferences as well as a set of candidate plans to be ranked based on these criteria. Then, the Electre III outranking method is applied to get a classifying of candidate plans. Finally, we carry a sensitivity study by varying several parameters of the method to get the critical points that impact the final decision.

The rest of this paper is structured as follows; section 2 presents key concepts about Forward and Reverse Logistics as well as the planning in logistics and the proposed planning model in our case. Section 3 is devoted to the detailed presentation of the considered approach and the case study application. Section 4 gives a detailed description of the sensitivity analysis scenarios. The last section provides a synthesis of this work and some conclusions and future perspectives.

\section{Planning of reverse logistics}

\subsection{Reverse logistics}

FL is the responsible function of supplying, transforming, warehousing and transporting materials between suppliers and customers (Waters, 2003). The FSC is often constituted of several entities having their own interests and playing each a specific role. Tasks that we can find in a FSC are supply, production, warehousing, distribution and transport, sales, etc. (Mouloua, 2007). To persist, enterprises must manage these tasks in efficient manner.

\subsubsection{Reverse logistics concept}

Logistics domain is always evolving by the introduction of new techniques and applications. RL is an emerged extension of FL. It is the process of planning, implementing and controlling flows of raw materials, in process inventory, and finished goods, from the point of use back to a point of recovery or point of proper disposal (Biehla et al., 2007).

A RSC as illustrated in Fig. 1, is a succession of tasks from consumption point (or manufacturing point for industrial waste, or a distribution point in the case of retailers return) to recovery point, following four principal tasks (Giuntini \& Andel , 1995; Rogers \& Tibben-Lembke, 1999): entry, collection, sorting and test, and reprocessing. In the sorting step, the decision is taken for the next step of reprocessing, through five options (Thierry et al., 1995): repair, remanufacture, refurbish, component recovery or cannibalization, and recycling. 


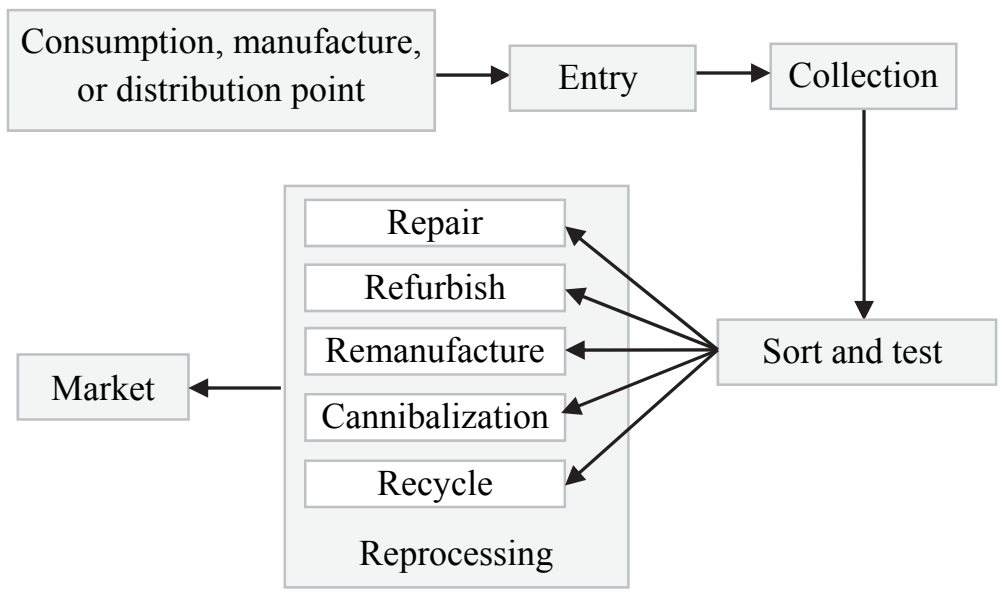

Fig. 1. General schema of RSC

The DWM is considered as a RSC, regarding to the reverse flow of products (i.e. DW) from consumer to recovery and reprocessing facilities.

\subsubsection{Domestic Waste Management}

The DWM is an important sector of the RSC domain. Based on definition given in (Guide, 2009), DW is considered as heterogonous residues constituted from:

- Remainders of any nature generated by population (food waste, kitchen residues, clothes, newspapers, etc.),

- Waste of desks, shops, industries and administrations, waste of gardens, etc.,

- Remainders of occasional exhibitions, markets, etc.,

- Residues of institutions like barracks, schools, universities, prisons, etc., This exludes:

- Building waste, gravel, building workshops remainders, etc.,

- Industrial waste,

- Anatomic and infecting waste, from hospitals and abattoirs and objects that can bring bacteriologic or drug pollutions,

- Big objects.

From official statistics given in (Guide, 2009), we notice that the organic part is dominating DW composition, but materials like plastic and paper represent also an important part. Taking into account generated quantities of DW, we can say that these components represent a real added value. However, Brito et al. (2002) consider the condition of retuned product and its quality as the crucial criteria for the choice of reprocessing step (Fig. 1) in RSC. There are numerous recovery options to get an added value from DW. The commonly applied techniques in many countries are (Guide, 2009): recycling, incineration (energy or heat recovery), and composting (produced compost is used as soil fertilizer).

\subsection{Planning models}

\subsubsection{Planning in logistics}

To maximize recovered amount from DW, an efficient RL strategy could be applied. Decisions structure in a supply chain represents natural hierarchy of interconnection (Bostel et al., 2005) and those decisions are ranked in three categories, strategic, tactic and operational. Naturally, this hierarchy is 
also existing in RSC. The strategic planning concerns the long term decisions with several tasks like collection strategy, zones limitations, facilities location and transportation fleet. The tactic planning is devoted to the mean term with the decisions of collection tourneys planning, affectation of trucks and operators to zones, etc. The operational planning concerns the short term decisions of daily collection program, urgent cases, etc. Our model is considered in the strategic level, because it concerns the study of DWM to adopt an effective collection strategy. Among the well-known techniques to resolve multiobjective problems, our choice is oriented to MCDM approach. MCDM had emerged in the last century to deal with real complex problems. Munier (2011) mentioned several applications of this approach. He mentions models developed in transportation, water resources distribution, military operations, urban planning, waste management, etc.

\subsubsection{The multicriteria model}

MCDM has the purpose of giving indices for the DM in the perspective to make a rational decision. Our aim is to rank several alternatives or management plans (we use here the terms 'alternative' and 'plan' interchangeably to indicate the same concept) evaluated on multiple criteria. We opted to MCDA for the two main reasons. First, quantifying of all parameters is not always feasible in DWM area. Second, this model can be adapted to be used in combination/after other methods, concentrating the search on a smaller region of search space.

Typically, a MCDM demarche is constituted from following steps. First, it begins by specifying the objective or the type of the decision to make (choice, sorting, ranking, etc.). Then, a set of candidate alternatives and a family of evaluation criteria are elaborated. This will allow the construction of the performance table by evaluating alternatives relative to all criteria. An aggregation technique is applied on this table in order to give the result corresponding to the stated objective. Some techniques may require additional data like criteria importance or thresholds to do this aggregation. Finally, a sensitivity analysis is usually recommended to evaluate obtained result.

\section{Proposed approach and application}

The model proceeds by comparing different DWM plans to get a ranking of them. This will give the DM information about the convenient decision to take relative to the entered data. The general schema of the model (Benzohra \& Noureddine, 2015) is illustrated in the Fig. 2. It consists of candidate plans that will be evaluated based on a family of criteria. Then, using the Electre III method (Roy, 1978; Vallée \& Zielniewicz, 1994; Pena et al., 2007), the model gives a partial preorder of plans.

The main advantage of the Electre III method is that it permits to deny compensation by the mean of veto threshold. This is useful in case of criteria with critical character like those relative to health and environment. In addition, this method takes in consideration data uncertainties by the preference and indifference thresholds.

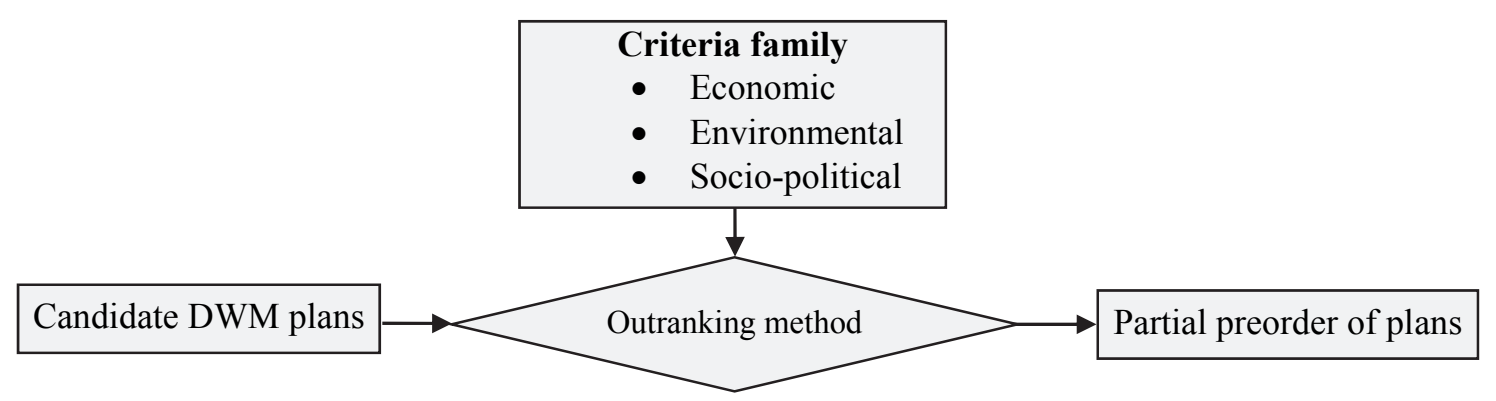

Fig. 2. General schema of the model 


\subsection{Definition of the model}

Fig. 3 represents DW network in Algeria. Random disposition still exist with anarchic landfill that has dangerous environmental and health effects beside additional costs. Despite colossal efforts, actual DWM remain not efficient. Several problems are remarked in the actual management plan.

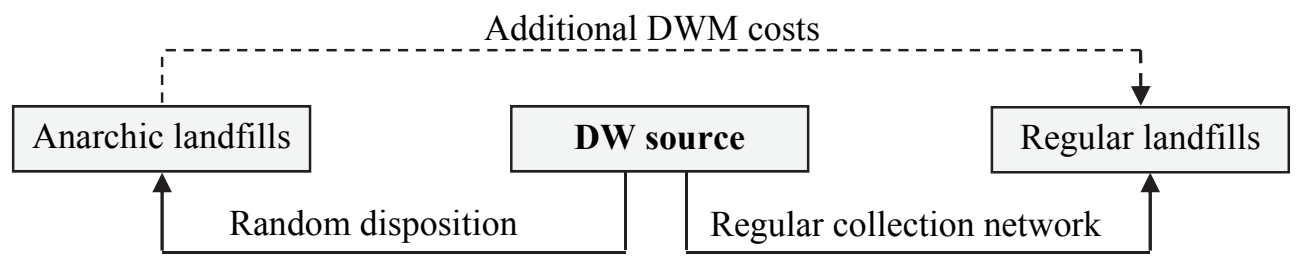

Fig. 3. DWM network in Algeria

For our purpose, we preselected a set of candidate DWM plans and evaluation criteria after domain experts' consultations and literature review (Chenayah \& Takeda, 2005; Hokkanen \& Salminen, 1997; Karagiannidis \& Moussiopoulos, 1997).

The inputs of the model, identified in (Benzohra \& Noureddine, 2015), are the five management plans (Table 1) as alternatives to be ranked and the fourteen criteria (Table 2), characterised by an optimization sense either of maximizing or minimizing type.

\section{Table 1}

Candidate plans

\section{Code}

A1 Actual plan of DWM in Algeria

A2 Sort at source

A3 Sort at source by dedicated operators

A4 A1 + buying materials from specialized collectors

A5 Incineration and heavy metals sorting

\section{Table 2}

Criteria list

\begin{tabular}{|c|c|c|}
\hline Code & Criteria & Type \\
\hline \multicolumn{3}{|c|}{ Economic criteria } \\
\hline $\mathrm{g} 1$ & Facilities costs & Min \\
\hline g2 & Human resources costs & Min \\
\hline g3 & Costs of awareness creation & Min \\
\hline g4 & Waste collection costs & Min \\
\hline g5 & Recovered materials & Max \\
\hline g6 & Recovered materials quality & Max \\
\hline \multicolumn{3}{|c|}{ Environment criteria } \\
\hline $\mathrm{g} 7$ & Visual impact & Min \\
\hline g8 & Pollution & Min \\
\hline g9 & Noises & Min \\
\hline \multicolumn{3}{|c|}{ Socio-political criteria } \\
\hline $\mathrm{g} 10$ & Quality of service & Max \\
\hline g11 & Jobs creation & Max \\
\hline g12 & Specific problems & Min \\
\hline g13 & Social and health problems & Min \\
\hline g14 & Plan applicability & Max \\
\hline
\end{tabular}




\subsection{Application of the model}

\subsubsection{Evaluation of criteria}

This numerical evaluation was obtained from our previous study (Benzohra \& Noureddine, 2015). Technical landfill center (TLC) engineer represents in this case the DM role. The DM estimated the criteria values for each candidate plan. Table 3 shows the given values.

Table 3

Performance table

\begin{tabular}{ccccccccccccccc}
\hline & $\mathrm{g} 1$ & $\mathrm{~g} 2$ & $\mathrm{~g} 3$ & $\mathrm{~g} 4$ & $\mathrm{~g} 5$ & $\mathrm{~g} 6$ & $\mathrm{~g} 7$ & $\mathrm{~g} 8$ & $\mathrm{~g} 9$ & $\mathrm{~g} 10$ & $\mathrm{~g} 11$ & $\mathrm{~g} 12$ & $\mathrm{~g} 13$ & $\mathrm{~g} 14$ \\
\hline A1 & 7 & 5 & 3 & 5 & 1 & 3 & 5 & 9 & 9 & 5 & 6 & 2 & 8 & 5 \\
A2 & 17 & 3 & 10 & 8 & 9 & 10 & 1 & 3 & 5 & 9 & 9 & 1 & 1 & 8 \\
A3 & 6 & 5 & 7 & 6 & 7 & 6 & 3 & 5 & 3 & 8 & 8 & 1 & 1 & 6 \\
A4 & 15 & 6 & 5 & 5 & 5 & 4 & 4 & 7 & 7 & 6 & 7 & 3 & 7 & 9 \\
A5 & 10 & 6 & 8 & 7 & 7 & 5 & 3 & 2 & 9 & 7 & 6 & 1 & 1 & 5 \\
wj $^{(\text {(a) }}$ & 6 & 6 & 4 & 4 & 6 & 7 & 5 & 10 & 5 & 8 & 5 & 2 & 4 & 6 \\
qj $^{(b)}$ & 1 & 1 & 1 & 1 & 1 & 1 & 1 & 1 & 1 & 1 & 1 & 1 & 1 & 1 \\
pj $^{(\text {(c) }}$ & 2 & 2 & 2 & 2 & 2 & 2 & 2 & 2 & 2 & 2 & 2 & 2 & 2 & 2 \\
jj $^{(d)}$ & 10 & $/$ & $/$ & $/$ & $/$ & $/$ & $/$ & 3 & $/$ & $/$ & $/$ & $/$ & 3 & 3 \\
\hline
\end{tabular}

(a, b, c and d) weight, indifference threshold, preference threshold and veto threshold of the criterion $\mathrm{j}$

To attribute criteria weights, the DM begin by giving the highest value to the most important criteria then give weight values to other criteria relative to this highest value. The selected value of indifference threshold is $\mathrm{qj}=1$ for all criteria. This choice appears to be reasonable to take into account small judgment errors. On the other hand, the chosen preference threshold was $\mathrm{pj}=2$. Due to their critical character, a veto threshold (vj)was assigned to criteria g1, g8, g13 and g14 as shown in table 3 . The rest of criteria with less importance was not given the veto right.

\subsubsection{Results and discussion}

To apply the Electre III method, we have used the software Electre 34 (Mayag, 2014).

The Concordance indices are obtained by agregating per critirion comparisons of each two alternatives. The matrix of these indices is shown in Fig. 4 (a). To illustrate the principle of compensation inhibition, let's take an example of two alternatives A1 and A2. On the entirety of criteria, concordance indices of $\mathrm{A} 1$ and $\mathrm{A} 2$ are $\mathrm{C}(\mathrm{A} 1, \mathrm{~A} 2)=0,21$ and $\mathrm{C}(\mathrm{A} 2, \mathrm{~A} 1)=0,82$. This means that $\mathrm{A} 2$ is better than $\mathrm{A} 1$ even the fact that $\mathrm{A} 1$ evaluation on $\mathrm{g} 1$ criterion is better than $\mathrm{A} 2$ evaluation. To avoid this indisired compensation, Electre III method uses the credibility indices to confirm or reject concordance. The credibility index is obtained from concordance index weakened by discordance indix which is based on veto thresholds.

Credibility matrix is illustrated in Fig. 4 (b). In our example, we notice that A2 is no longer outranking $\mathrm{A} 1$ and this is due to the veto effect of $\mathrm{g} 1$ criterion, despite high performances of $\mathrm{A} 2$ plan on most part of other criteria. The difference $\mathrm{g} 1(\mathrm{~A} 2)-\mathrm{g} 1(\mathrm{~A} 1)=10$ is larger or equal to $\mathrm{v}(\mathrm{g} 1)$, activated the veto effect resulting to a zero credibility $\mathrm{d}(\mathrm{A} 2, \mathrm{~A} 1)=0$.

This represents the first part of the Electre III method. It gives a fuzzy outranking relation of alternatives where credibility indices may show indecision situations.

The second part of the method i.e. the ascendant and descendant distillation gave results represented at the final outranking graph shown on the Fig. 4 (c)

From the outranking graph, we notice that the Alternative A2 outrank A5, which is outranking A3 and A4 whom are outranking A1. 


\begin{tabular}{|c|c|c|c|c|c|}
\hline & A. & A2 & A3 & A4 & A5 \\
\hline A1 & 1 & 0.21 & 0.36 & 0.65 & 0.49 \\
\cline { 2 - 6 } A2 & 0.82 & 1 & 0.82 & 0.76 & 0.87 \\
\cline { 2 - 6 } A3 & 0.95 & 0.42 & 1 & 0.81 & 0.87 \\
\cline { 2 - 6 } A4 & 0.87 & 0.32 & 0.45 & 1 & 0.64 \\
\cline { 2 - 6 } A6 & 0.82 & 0.38 & 0.79 & 0.76 & 1 \\
\hline
\end{tabular}

(a) Concordance matrix

\begin{tabular}{|c|c|c|c|c|c|}
\hline $\mathrm{A}$ & $\mathrm{A} 1$ & $\mathrm{~A} 2$ & $\mathrm{~A} 3$ & $\mathrm{~A} 4$ & $\mathrm{~A} 5$ \\
\hline $\mathrm{A} 1$ & 1 & 0 & 0 & 0 & 0 \\
\cline { 2 - 6 } $\mathrm{A} 2$ & 0 & 1 & 0 & 0.76 & 0.87 \\
\cline { 2 - 6 } $\mathrm{A} 3$ & 0.95 & 0.42 & 1 & $\mathbf{0}$ & 0 \\
\cline { 2 - 6 } $\mathrm{A} 4$ & 0.87 & 0 & 0 & 1 & 0 \\
\cline { 2 - 6 } $\mathrm{A} 5$ & 0.82 & 0 & $\mathbf{0 . 7 9}$ & $\mathbf{0}$ & 1 \\
\hline
\end{tabular}

(b) Credibility matrix

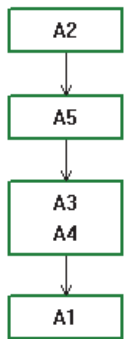

(c) Outranking graph

Fig. 4. Initial results

\section{Sensitivity study}

To perform sensitivity study, we have generated several scenarios by the variation of criteria characteristic parameters. The initial scenario is referred to be S1 scenario and sensitivity study scenarios are numbered from S2 to S13. So, first we acted on thresholds values. Then, to see the effects of changing weights we divided the work on three groups of scenarios depending on the categories of criteria to be altered. To perform this study, we have used also the Electre 34 software to generate gradually intervals of variation of thresholds and weights. All sensitivity scenarios are summarised in the Table 4.

Table 4

Sensitivity study scenarios

\begin{tabular}{|c|c|}
\hline Scenario & Description \\
\hline S1 & Initial scenario \\
\hline S2 & $q j=0$ \\
\hline S3 & $q j=p j=2$ \\
\hline S4 & Increase veto threshold of g1 \\
\hline S5 & Decrease veto threshold of g8 \\
\hline S6 & Increase veto threshold of g8 \\
\hline S7 & Increase veto threshold of g14 \\
\hline S8 & Increase economic criteria weights \\
\hline S9 & Decrease economic criteria weights \\
\hline S10 & Increase environmental criteria weights \\
\hline S11 & Decrease environmental criteria weights \\
\hline S12 & Increase socio-political criteria weights \\
\hline $\mathrm{S} 13$ & Decrease socio-political criteria weights \\
\hline
\end{tabular}

\subsection{Variation of thresholds}

\subsubsection{Thresholds of indifference and preference}

S2 and S3 scenarios act on the values of indifference and preference thresholds as follows:

- $\mathrm{S} 2: \mathrm{qj}=0$

- $S 3: q j=p j=2$

Applying these scenarios we obtained the graphs S2 and S3 of the Fig. 5. This shows a little difference relative to the initial scenario. In S2, eliminating indifference threshold effect permitted to differentiate the A3 and A4 plans to be in separate classes. However in S3 where indifference threshold was expended, three plans A2, A3 and A4 were in ex- æquo class. 


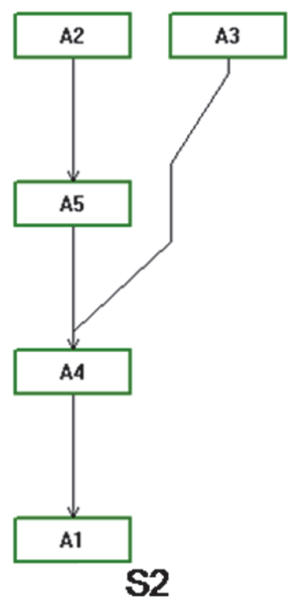

Fig. 5. Scenarios for variation of indifference and preference thresholds

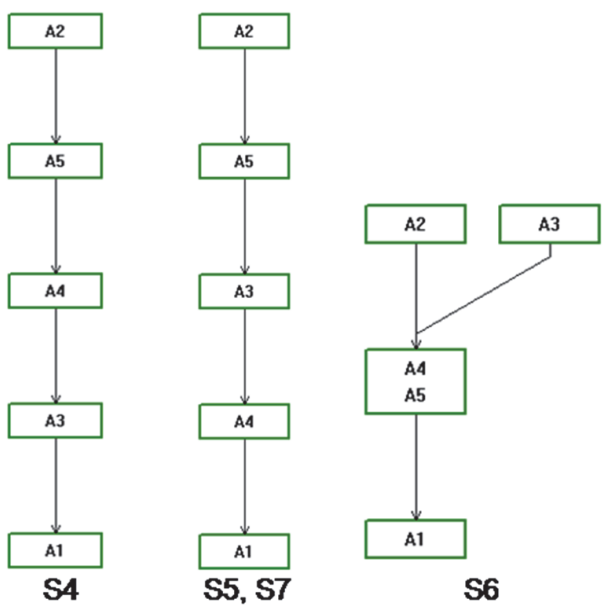

Fig. 6. Scenarios for variation of veto threshold

\subsubsection{Veto threshold}

In the initial scenario, veto threshold affected the final ranking. The goal here is to see the value of threshold that influences results.

- g1 criterion: we increase the veto threshold beginning from initial value $\mathrm{v}(\mathrm{g} 1)=10$. When we arrive to a value of 12.64, we notice an alteration of the final ranking as shown in Fig. 6-S4. However, in the case of decreasing the value of veto threshold we obtain graph of Fig. 6-S5. We remark a limited alteration on the final ranking. This is due to the large value of veto threshold which is greater than differences that exist between alternatives evaluation on this criterion.

- g8 criterion: we increase the veto threshold progressively from initial value $v(g 8)=3$. Attaining a value of 3.1 we notice alteration on the ranking as illustrated at the Fig. 6-S6. In the case of decreasing no alteration is observed. This result shows the importance of taking carefully the value of this threshold because it is influencing rapidly the final ranking and its value is close to differences that exist between alternatives evaluations.

- g13 criterion: the changes applied on the veto threshold of this criterion doesn't have any impact on the results. This can be interpreted by the fact that alternatives having bad evaluations on this criterion are already in the bottom of the ranking, and their rank was influenced by veto thresholds of other criteria.

- g14 criterion: increasing the value of the veto threshold of this criterion we obtain the graph of Fig. 6-S7 with $\mathrm{v}(\mathrm{g} 14)=3.07$. For decreasing case the final ranking remain unchanged. We can give the same interpretation as in the case of $\mathrm{g} 8$ criterion.

\subsection{Variation of weights}

\subsubsection{Economic criteria}

The S8 and S9 scenarios are created by increasing (S8) and decreasing (S9) weights of economic criteria.

- S8 : weights are increased by a value of 2.43 . Under this value no changes are observed. However, when attaining 2.43, we obtain ranking shown in Fig. 7-S8.

- S9 : when we decrease weights by of value of 3.28, the ranking is changed as in Fig. 7-S9. 
S8 scenario shows that increasing weights of economic criteria boosts the ranking of A4 alternative. This is due essentially to the well-balanced economic performance of A4. In the case of decreasing of weights A3 is no longer outranked by A5. Globally, we can say that ranking was not suddenly altered.

\subsubsection{Environmental criteria}

We create also S10 and S11 scenarios that represent increasing (S10) and decreasing (S11) of environmental criteria weights.

- S10: where we increase weights by 7.63, we remark an alteration of plans ranking as in Fig. 7S10.

- S11: in this scenario we decrease weights by 5.321 for $\mathrm{g} 8$ and 4.999 for $\mathrm{g} 7$ and $\mathrm{g} 9$. This give the graph of Fig. 7-S11.

By increasing weights of environmental criteria, A4 alternative become outranked by A2 only. In the two scenarios, A4 is outranking A3. This is due the mediocre performances of A3 and A5 in the environmental aspect.

\subsubsection{Socio-political criteria}

Again the S12 and S13 scenarios are created by increasing (S12) and decreasing (S13) weights of sociopolitical criteria.

- S12: increasing weights by a value of 28.80, ranking changes as in Fig. 7-S12.

- S13: In the case of decreasing weights by 1.999 for $g 12$ and 3.33 for g10, g11, g13 and g14 the ranking becomes as shown in Fig. 7-S13.

In the case of increasing weights values, the final ranking is not altered immediately. This can be caused by approached performances of alternatives on the most important socio-political criteria.

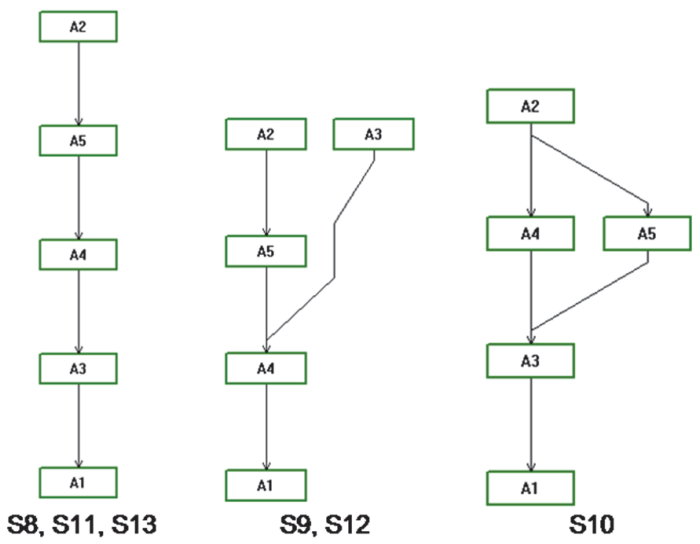

Fig. 7. Scenarios for variation of weights

\section{Synthesis and Conclusion}

We worked on RL planning which is considered to be a highly constrained process. Our study concerned the DWM an annoying problem for all cities. DWM is an application of RL with multiple objectives to take in account at same time. MCDM is an interesting approach to solve real decision and planning problems. The used method Electre III offers realist results. This is due to its mechanism such as thresholds, which permit to deal with problems like uncertain data, critical aspects to take into account and others. This study was based on the Algerian case, and we gathered data from a sea side city characterised by high population density. A sensitivity study was carried out, and this permit to evaluate positively this investigation. Sensitivity study shows a relative stability of results. Ranks of alternatives were not changed in the same time or brutally and the twelve scenarios had a minor influence on the ranking. This indicates a relative robustness of results. The most attracting remark 
from this sensitivity study is that Alternative A2 which represents 'sort at source' dominated other alternatives. This management option is really the ideal solution from the sustainability perspective, but it still have some constraints. A3 and A5 plans appeared to be very interesting during this sensitivity study. The actual plan A1 was evidently dominated and it is not efficient from economic, environmental and socio-political perspectives and must be replaced. Future works, may concern the application of other methods to compare obtained result in order to validate and generalise this decision framework to solve different situations.

\section{References}

Benzohra, A., \& Noureddine, M. (2015). Management planning of domestic wastes. Annals of Computer Science Series, 13(1), 17-23.

Biehl, M., Prater, E., \& Realff, M. J. (2007). Assessing performance and uncertainty in developing carpet reverse logistics systems. Computers \& Operations Research, 34(2), 443-463.

Riopel, D., Langevin, A., \& Campbell, J. F. (2005). The network of logistics decisions. In Logistics Systems: Design and Optimization (pp. 1-38). Springer US.

Chenayah, S., \& Takeda, E. (2005). PROMETHEE multicriteria analysis for evaluation of recycling strategies in Malaysia (No. 05-01).

Brito, M. P., Flapper, S. D. P., \& Dekker, R. (2002). Reverse Logistics: a review of case studies. ERIM Report Series Research in Management, Econometric Institute Report EI 2002-21.

Millet, D. (2011). Designing a sustainable reverse logistics channel: the 18 generic structures framework. Journal of Cleaner Production, 19(6), 588-597.

Giuntini, R., \& Andel, T. (1995). Master the six R's of reverse logistics. Transportation and Distribution, 36(3), 93-98.

Guide. (2009). Guide des techniciens communaux pour la gestion des déchets ménagers et assimilés. Algerian Ministry of environment \& United Nation Program for Development.

Hokkanen, J., \& Salminen, P. (1997). Choosing a solid waste management system using multicriteria decision analysis. European Journal of Operational Research, 98(1), 19-36.

Karagiannidis, A., \& Moussiopoulos, N. (1997). Application of Electre III for the integrated management of municipal solid wastes in the Greater Athens Area. In Multiple Criteria Decision Making (pp. 568-578). Springer Berlin Heidelberg.

Mayag, B. (2014). Electre 34 software downloaded from : http://amsade.dauphine.fr/ $\sim$ mayag/links.html

Mouloua, Z. (2007). Ordonnancements coopératifs pour les chaînes logistiques (Doctoral dissertation, Institut National Polytechnique de Lorraine-INPL).

Munier, N. (2011). A strategy for using multicriteria analysis in decision-making: a guide for simple and complex environmental projects. Springer Science \& Business Media.

Pena, R. R., Rebollo, L. P., Gibert, K., \& Valls, A. (2007). Use and evaluation of Electre III/IV. Universitat Rovira i Virgili.

Rogers, D. S., \& Tibben-Lembke, R. S. (1999). Going backwards: reverse logistics trends and practices (Vol. 2). Pittsburgh, PA: Reverse Logistics Executive Council.

Roy, B. (1978). Electre III: Un algorithme de classement fondé sur une représentation floue des préférences en présence de critères multiples. Cahiers du CERO, 20(1), 3-24.

Thierry, M., Salomon, M., Van Nunen, J., \& Van Wassenhove, L. (1995). Strategie issues in product recovery management. California Management Review, 37(2), 114-135.

Vallée, D., \& Zielniewicz, P. (1994). Electre -IV, version 3. x(aspects méthodologiques. Tome 1).

Waters, D. (2003). Logistics: an introduction to supply chain management.

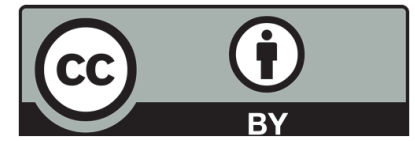

(C) 2016 by the authors; licensee Growing Science, Canada. This is an open access article distributed under the terms and conditions of the Creative Commons Attribution (CC-BY) license (http://creativecommons.org/licenses/by/4.0/). 